\title{
Pseudobrânquia do guaru Poecilia reticulata (Peter, 1859): análise estrutural, morfométrica e histoquímica para detecção de glicoconjugados ${ }^{1}$
}

\author{
Thiago L. Rocha ${ }^{2}$, Ana P.R. Santos ${ }^{2}$ e Simone M.T. Sabóia-Morais ${ }^{2 *}$
}

\begin{abstract}
Rocha T.L., Santos A.P.R. \& Sabóia-Morais S.M.T. 2013. [Pseudo-gill of guppy, Poecilia reticulata (Peter, 1859): structural, morphometric, and histochemical analyses for the detection of glycoconjugates.] Pseudobrânquia do guaru Poecilia reticulata (Peter, 1859): análise estrutural, morfométrica e histoquímica para detecção de glicoconjugados. Pesquisa Veterinária Brasileira 33(5):669-673. Laboratório de Comportamento Celular, Departamento de Morfologia, Instituto de Ciências Biológicas, Universidade Federal de Goiás, Campus II, ICB IV, Cx. Postal 131, Goiânia, GO 74001-970, Brazil. E-mail: simonesaboias@gmail.com

The morphology, cytomorphometric parameters, and glycoconjugates present in the pseudo-gill of guppy, Poecilia reticulata Peter, 1859 (Cyprinodontiformes: Poeciliidae), were investigated by light microscopy coupled to image capture and analysis system, and also by lectin histochemistry. The microscopic anatomy indicates that $P$. reticulata has a glandular pseudo-gill formed by two lobes, located underneath the pharynx epithelium. The organ is formed by vascularized parenchyma rich in pseudo-gill cells. This cell type exhibits active cytophysiological state with an abundant system of biomembranes and lacking of ostium in apical surface, which in turn is found in the mitochondria-rich cells of the holobranch. This indicates that the pseudo-gill cells distinguishe from the holobranch cells in their morphology, histochemistry and physiology. Due to these intrinsic characteristics, the pseudo-gill of guppy fingerlings may have non-respiratory function in the initial phase of their development. The characterization of guppy's pseudo-gill could facilitate further studies about the effect of water pollutants on biomonitor species, such as P. reticulata.
\end{abstract}

INDEX TERMS: Guppy, Poecilia reticulata, gills, chloride cells, biomonitor species.

RESUMO.- A morfologia, os parâmetros citomorfométricos e os glicoconjugados presentes na pseudobrânquia de guaru, Poecilia reticulata Peter, 1859 (Cyprinodontiformes: Poeciliidae), foram investigados por microscopia de luz acoplada ao sistema de captura e análise de imagens, juntamente por histoquímica com lectinas. A anatomia microscópica indicou que $P$. reticulata possui pseudobrânquia glandular formada por dois lóbulos, a qual se localiza abaixo do epitélio faringiano. 0 órgão é constituído por parênquima vascularizado e rico em células pseudobranquiais. Esse tipo celular exibe estado citofisiológico ativo, com abundante sistema de biomembranas e ausência de óstio

\footnotetext{
${ }^{1}$ Recebido em 20 de outubro de 2012.

Aceito para publicação em 7 de março de 2013.

${ }^{2}$ Laboratório de Comportamento Celular, Departamento de Morfologia, Instituto de Ciências Biológicas, Universidade Federal de Goiás (UFG), Campus II, ICB IV, Cx. Postal 131, Goiânia, GO 74001-970, Brasil. *Autor para correspondência: simonesaboias@gmail.com
}

na superfície apical,que por sua vez é encontrado nas células ricas em mitocôndrias das holobrânquias. Assim, indica-se que as células da pseudobrânquia se distinguem das células das holobrânquias em relação à morfologia, histoquímica e fisiologia. Em decorrência dessas características intrínsecas, a pseudobrânquia de alevinos do guaru pode desempenhar funções não respiratórias nas fases iniciais do desenvolvimento. Além disso, a caracterização da pseudobrânquia do guaru possibilitará estudos futuros sobre o efeito de poluentes aquáticos em espécies biomonitoras, como $P$. reticulata.

TERMOS DE INDEXAÇÃO: Guaru, Poecilia reticulata, brânquias, células do cloro, espécie bioindicadora.

\section{INTRODUÇÃO}

As brânquias dos teleósteos são órgãos multifuncionais e desempenham, além da íon/osmorregulação, funções de trocas gasosas, respiração, regulação ácido-base, gus- 
tação e recepção de estímulos do meio externo, excreção de produtos nitrogenados e secreção de substâncias protetoras contra a irritação provocada por agentes externos, tais como organismos patógenos e poluentes do ambiente aquático (Wilkie 1997, Machado \& Fanta 2003, Díaz et al. 2005, Borges-de-Oliveira et al. 2006, Vigliano et al. 2006).

A complexidade das brânquias dos peixes como órgãos multifuncionais é reflexo de seu epitélio de revestimento (Sabóia-Morais et al. 1996) e dos tipos celulares que se interagem para a manutenção das funções branquiais. Assim, a presença ou ausência dessas células, juntamente com sua morfofisiologia, distribuição, abundância, densidade e constituição bioquímica é variada entre as espécies de peixes e entre os estágios do desenvolvimento (Rocha et al. 2010).

As brânquias são evaginações da superfície do corpo dos peixes e encontram-se no interior das bolsas faríngeas (Pough et al. 1999). Elas são compostas por dois conjuntos de holobrânquias, sendo que cada uma dessas consiste de um arco branquial, do qual partem projeções denominadas de filamentos branquiais na região caudo-lateral. Destes filamentos saem projeções radiais (lamelas branquiais) em sua superfície dorsal e ventral. De cada arco branquial partem rastelos branquiais em direção oposta a dos filamentos (Vigliano et al. 2006). Esta organização permite um aumento da área do epitélio branquial que entra em contato com o meio externo, proporcionando a esta estrutura uma superfície respiratória e íon osmorregulatória.

Devido às suas propriedades morfofisiológicas, bioquímicas, moleculares e celulares, localização anatômica e capacidade de biotransformação e bioacumulação de contaminante ou poluente do ambiente aquático, as holobrânquias dos teleósteos têm sido utilizadas para análise dos efeitos tóxicos da poluição aquática em órgãos-alvo de peixes (Larini 1979, Fanta et al. 2003). Contudo, ainda pouco se conhece sobre a organização estrutural, funções e alterações provocadas por poluentes nas pseudobrânquias dos peixes.

O sistema-modelo investigado foi Poecilia reticulata, pertencente à ordem Cyprinodontiformes, família Poeciliidae e subfamília Poeciliinae. Essa espécie é indicada para estudos toxicológicos pela Organização para Cooperação e Desenvolvimento Econômico (OECD) (OECD 1992). Esta espécie possui ampla distribuição biogeográfica, fácil disponibilidade e reprodução ao longo das estações do ano e dimorfismo sexual.

A utilização do guaru como espécie sentinela em programas de biomonitoramento tem sido comprovada por diversos autores, tais como nos estudos dos efeitos tóxicos de tributiltina e bisfenol A (Haubruge et al. 2000), metais pesados como cloreto de cádmio (Yilmaz et al. 2004), disruptores endócrinos como o fungicida vinclozolin, o metabólico do DDT (p,p'-DDE) e o flutamide (Baatrup \& Junge 2001), além do octilfenol e 17ß-estradiol (Kinnberg et al. 2003). Nesse sentido, este trabalho pretendeu descrever a morfologia e os glicoconjugados presentes na pseudobrânquia da espécie bioindicadora Poecilia reticulata (Peter 1859), com o intuito de disponibilizar conhecimentos sobre a estrutura normal desse órgão para análises subcelu- lares, celulares e histológicas futuras, que utilizarão esta estrutura como biomarcador da poluição aquática.

\section{MATERIAL E MÉTODOS}

O presente projeto foi aprovado pelo Comitê de Ética e Pesquisa Humana e Animal do Hospital das Clinicas da UFG, e está protocolado sob no 049 desde 2008, e seguiu os princípios éticos para pesquisa animal determinados pelo Colégio Brasileiro de Experimentação Animal (COBEA) (COBEA 1991).

\section{Sistema modelo}

Espécimes de fêmeas adultas de Poecilia reticulata foram coletados em tanques localizados na Escola de Medicina Veterinária da Universidade Federal de Goiás, Campus II, Goiânia, GO ( $16^{\circ} 35^{\prime} 37^{\prime \prime} \mathrm{S}$ e $49^{\circ} 16^{\prime} 50^{\prime \prime} \mathrm{W}$ ) e transferidas para o Laboratório de Comportamento Celular (LCC), localizado no Instituto de Ciências Biológicas, da Universidade Federal de Goiás (ICB/UFG). Em seguida, os espécimes passaram por um período de aclimatação de 14 dias em aquários de 40 litros de água doce sem cloro, com $\mathrm{pH}$ de $6,9 \pm 0,1$. A temperatura da água foi mantida a $\pm 27^{\circ} \mathrm{C}$ e o fotoperíodo era de ciclos com 12:12 horas claro/escuro. 0 quantitativo de amônia dissolvida na água era de 0 a $0,01 \mu / \mathrm{L}$. Os animais foram alimentados três vezes ao dia com ração comercial (alconCOLOURS ${ }^{\circledR}$ ), a qual possui $44 \%$ de proteína bruta. Os restos de alimento e fezes eram removidos diariamente com auxílio de sifão, e o volume da água removido era reposto logo a seguir.

Após a aclimatação, retiraram-se aleatoriamente do tanque de adaptação 10 fêmeas no estágio final de prenhez, ou seja, com região ventral dilatada, e que por transparência era possível visualizar as larvas, tal como descrito por Rocha et al. (2010). As fêmeas foram separadas individualmente em tanques-maternidade com 40 litros de água até o nascimento dos alevinos.

\section{Processamento do material biológico}

Após o nascimento, os alevinos com $0,0084 \pm 0,0011 \mathrm{~g}$ de massa total e $0,92 \pm 0,07 \mathrm{~cm}$ de comprimento total foram divididos em dois grupos: 10 animais fixados por imersão em solução de Karnovsky (glutaraldeído 2,5\% (v/v), paraformaldeído 4\% (p/v) e tampão fosfato de sódio 0,1M pH 7,2) (Karnovsky, 1965) por 2 horas, e 10 animais fixados por imersão em tetróxido de ósmio e iodeto de zinco (ZIO), de acordo com Watrin \& Mayer-Gostan (1996) e Schreiber \& Specker (1999).

0 material fixado em Karnovsky foi dividido em dois grupos. 0 primeiro foi processado por técnicas histológicas convencionais para inclusão em parafina com plastificante (SEM, USA), seccionado com $4 \mu \mathrm{m}$ de espessura e submetido ao screening com 10 lectinas biotiniladas (Quadro 1) e revelado com estreptoavidina-

Quadro 1. Dados sobre nomeclatura, origem e açúcar ligante das lectinas biotiniladas

\begin{tabular}{|c|c|c|}
\hline Abreviação & Lectinas & Açúcares \\
\hline SBA & Soybean Agglutinin & $\alpha$-D-Gal, $\alpha$ - e $\beta$-Gal-Nac \\
\hline ECL & Erythrina Cristagalli Lectin & Gal, Galactosil $(\beta-1,4)$ Glc-Na \\
\hline VVL-B & Vicia Villosa Lectin & $\alpha-$ e $\beta$-Gal-Nac \\
\hline STLB & $\begin{array}{c}\text { Solanum Tuberosum (Potato) } \\
\text { Lectin }\end{array}$ & Glc-Nac \\
\hline LELB & $\begin{array}{c}\text { Lycopersicon Esculentum } \\
\text { (Tomato) Lectin }\end{array}$ & Glc-Nac \\
\hline $\mathrm{PHA}_{-\mathrm{E}_{4}}$ & $\begin{array}{c}\text { Phaseolus Vulgaris Erythroag- } \\
\text { glutinin }\end{array}$ & $\begin{array}{c}\text { D-Gal-Nac, estruturas } \\
\text { complexas }\end{array}$ \\
\hline UEA-I & Ulex Europaeus Agglutinin I & $\alpha$-L-Fucose \\
\hline WGA & Wheat Germ Agglutinin & D-GlcNAc e ácido siálico \\
\hline MAM & Maackia amurensis lectin & Ácido siálico \\
\hline COnA & Concanavalina A & $\alpha$-D-man e $\alpha$-D-glicose \\
\hline
\end{tabular}


-peroxidase (Dako Co, USA), de acordo com Paffaro Jr et al. (2003). O segundo grupo foi incluso em historesina (LEICA Historesin, USA) de acordo com as normas do fabricante, seccionados com $1 \mu \mathrm{m}$ de espessura no ultramicrótomo (LEICA, Ultracut UCT, USA) e corados com Azul de Toluidina 1\% (p/v) pH 8,4 (VETEC).

Os alevinos fixados com ZIO foram inclusos em parafina com plastificante (SEM, USA), seccionado com $4 \mu \mathrm{m}$ de espessura e corados com Azul de Alcian 1\% (p/v) pH 2,5 (VETEC). Todos os cortes histológicos foram obtidos através de secções transversais dos alevinos na região do primeiro arco branquial.

Fotomicrografias das pseudobrânquias foram obtidas por meio do microscópico fotônico (Leica DMLB, USA) acoplado ao sistema de captura de imagem câmera Samsung Color Digital SHC 410 NAD. A estereologia, também denominada de morfometria, foi realizada no Programa Image Pro-Plus 6.0 (Media Cybernetics, Silver Spring, EUA). Para tanto, foram mensuradas variáveis adaptadas por Vertemati et al. (2008) e Golalipour et al. (2009) (Quadro 2). A área e o diâmetro foram obtidos utilizando as ferramentas de contorno e medida de comprimento presentes no programa de análise de imagens Image Pro Plus 6.0, respectivamente.

Quadro 2. Variáveis mensuradas nas células pseudobranquiais divididas em volumétricas, área e diâmetro

\begin{tabular}{ll}
\hline \multicolumn{1}{c}{ Variáveis } & \multicolumn{1}{c}{ Medidas estimadas } \\
\hline Volumétricas & Citoplasma celular (Vcit = Vcel - Vnuc) \\
& Núcleo celular (Vnuc) \\
& Celular (Vcel) \\
Área & Citoplasma celular (Acit = Acel - Anuc) \\
& Núcleo celular (Anuc) \\
& Celular (Acel) \\
& Razão área núcleo/citoplasma (Anuc / Acit) \\
Diâmetro & Núcleo da célula (Dnuc = (Dnuc maior + Dnuc menor) $/ 2)$ \\
& Celular (Dhep = (Dhep maior + Dhep menor) $/ 2)$
\end{tabular}

O volume celular foi estimado considerando as células como esferas, conforme Ke et al. (2007), onde o volume é medido pela fórmula: $V=3 / 4 \pi r^{3}$. Para tanto, primariamente foi calculado o raio ( $r$ ) celular por meio da fórmula $A=\pi r^{2}$, a partir da área da circunferência medida pelo programa Image Pro-Plus 6.0 (Media Cybernetics, Silver Spring, EUA).

\section{RESULTADOS}

\section{Morfologia}

A pseudobrânquia de alevinos de Poecilia reticulata foi localizada próximo ao epitélio faringeano e possui lamelas e filamentos fundidos circundados por tecido conjuntivo, ao contrário das holobrânquias, as quais possuem filamentos e lamelas branquiais livres com ampla superfície de contato (Fig.1-4). Nesse teleósteo, a pseudobrânquia não é visível externamente nos alevinos. A morfologia microscópica indicou que a pseudobrânquia é dividida em dois lóbulos, cada lóbulo é preenchido principalmente por parênquima celular diferenciado, células pseudobranquiais, e uma parcela de células menores, com núcleo mais condensado.

A pseudobrânquia do guaru é uma estrutura altamente vascularizada, sendo que as células do parênquima formam cordões ao redor do sistema vascular (Fig.3-4). Pode-se identificar um vaso sanguíneo central contendo grande quantidade de hemácias nucleadas, o qual se ramifica em vasos de menores calibres para irrigação de toda a pseudobrânquia.

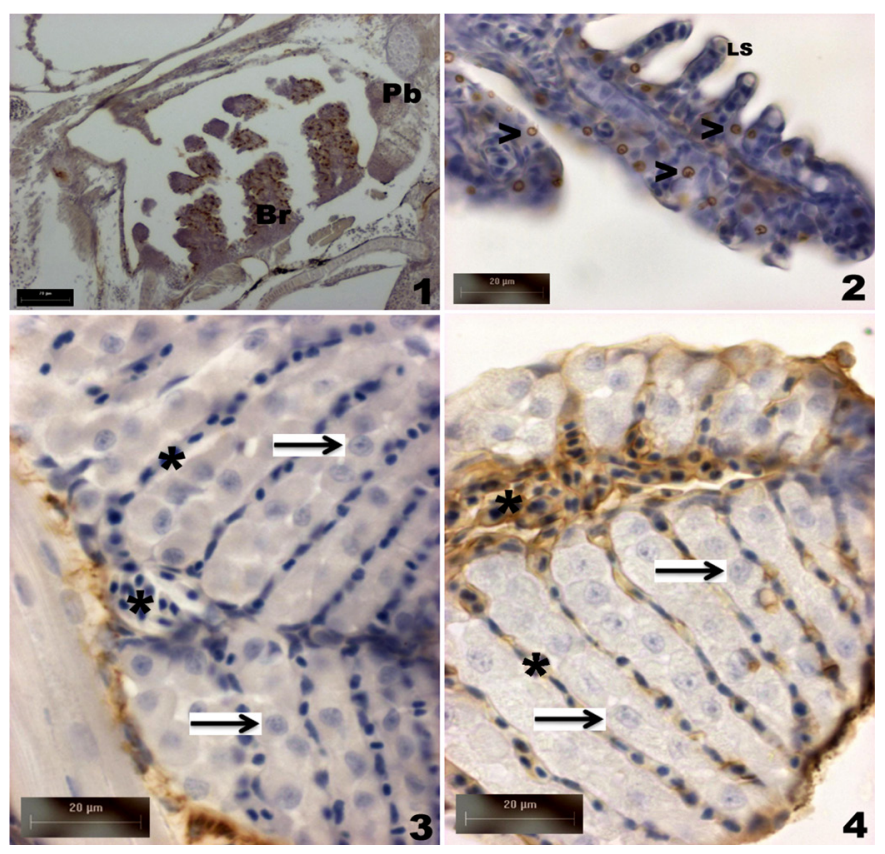

Fig.1-4. (1) Visão panorâmica das brânquias (Br) e da pseudobrânquia $(\mathrm{Pb})$ da larva (Fase 4$)$ de $P$. reticulata em secção longitudinal. Técnica: Lectina SBA. (2) Secção longitudinal das holobrânquias de alevinos do guaru apresentando células ricas em mitocôndrias (CRMs) com óstio reativo à lectina WGA no epitélio interlamelar (>) e as lamelas secundárias (LS) com ausência de CRMs. Técnica: Lectina WGA. (3) Secção longitudinal da pseudobrânquia de alevino do guaru destacando os vasos sanguíneos (*) e as CRMs sem óstio (setas). Técnica: lectina ECL-B. (4) Pseudobrânquia dos alevinos do guaru apresentando vasos sanguíneos com as hemácias reativas à lectina SBA $\left({ }^{*}\right)$, e as CRMs sem óstio (setas). Técnica: lectina SBA. Escala das barras nas Figuras 1-4 $=20 \mu \mathrm{m}$.

\section{Características das células pseudobranquiais}

O principal tipo celular encontrado na pseudobrânquia glandular de P. reticulata possui formato poligonal com área e volume citoplasmático de $35 \pm 9,75 \mu \mathrm{m}^{2}$ e $165,2 \pm 63,2 \mu \mathrm{m}^{3}$, respectivamente. 0 núcleo geralmente é central e arredondado, com abundante eucromatina e único nucléolo evidente (Fig.1, 3 e 4). A citomorfometria indicou que essas células estavam em constante atividade celular, principalmente devido à área nuclear grande $\left(7,9 \pm 1,6 \mu \mathrm{m}^{2}\right)$ e proporção área nuclear / área citoplasmática extensa $(0,23 \pm 0,05)$ (Quadro 3).

Quadro 3. Parâmetros citométricos das células pseudobranquiais de alevinos do guaru ( $P$. reticulata). Os dados estão apresentados na forma de média \pm desvio padrão

\begin{tabular}{lc}
\hline \multicolumn{1}{c}{ Parâmetros citométricos } & Valores \\
\hline Diâmetro celular $(\mu \mathrm{m})$ & $7,46 \pm 1,02$ \\
Área celular $\left(\mu \mathrm{m}^{2}\right)$ & $43,50 \pm 11,00$ \\
Volume celular $\left(\mu \mathrm{m}^{3}\right)$ & $221,67 \pm 78,70$ \\
Área citoplasmática $\left(\mu \mathrm{m}^{2}\right)$ & $35,83 \pm 9,75$ \\
Volume citoplasmático $\left(\mu \mathrm{m}^{3}\right)$ & $204,40 \pm 75,90$ \\
Diâmetro nuclear $(\mu \mathrm{m})$ & $3,30 \pm 1,02$ \\
Área nuclear $\left(\mu \mathrm{m}^{2}\right)$ & $7,90 \pm 1,60$ \\
Volume nuclear $\left(\mu \mathrm{m}^{3}\right)$ & $17,20 \pm 4,90$ \\
Proporção área nuclear/área citoplasmática & $0,23 \pm 0,05$
\end{tabular}


As células pseudobranquiais do $P$. reticulata possuem algumas características morfológicas semelhantes às células ricas em mitocôndrias (CRM), também denominadas de células do cloro ou ionócitos, tais como citoplasma abundante, núcleo e nucléolo evidentes e formato poligonal. Contudo, verificara-se que as células pseudobranquiais não possuem especializações de membrana apical denominadas de ósteos, estrutura presente em CRM (Fig.5-6).

A ausência do ósteo nas células pseudobrânquiais foi confirmada nas secções coradas com Azul de Toluidina pH 8,4 e naqueles marcados com a citoquímica de lectinas, a qual permite a marcação de carboidratos de glicoproteínas e/ou glicolipídios na superfície do ósteo (Fig.1, 3-6). As CRM das holobrânquiais podem apresentar ósteo marcado com as lectinas STLB e LELB ao contrário das células da pseudobrânquia.

As células pseudobranquiais, quando submetidas à técnica de ZIO, apresentaram reatividade positiva ao ZIO, de modo semelhante às CRM das holobrânquias. Contudo, a intensidade de reatividade foi maior no citoplasma das células pseudobranquiais quando comparado às CRM (Fig.7-8). Além disso, alguns condrócitos branquiais apresentaram reatividade fortemente positiva ao ZIO.

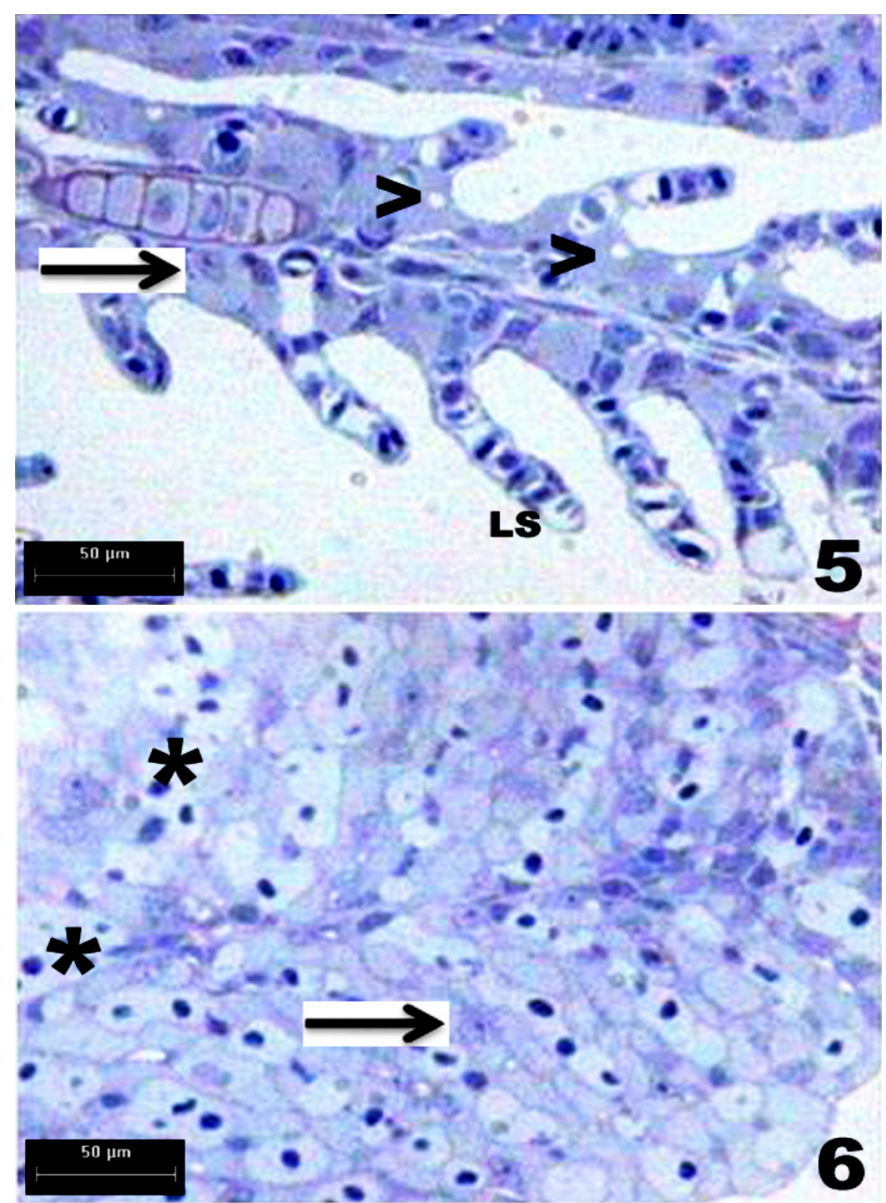

Fig.5-6. (5) Brânquias de alevinos do guaru em secção longitudinal. Observa-se as lamelas secundárias (LS) e, no epitélio interlamelar, CRM sem o óstio (seta) e CRM com óstio ( $>$ ). Técnica. AT pH 8,4. (6) Pseudobrânquia de alevino do guaru em secção longitudinal apresentando CRM sem óstio (seta) e os vasos sanguíneos (*). Técnica. AT pH 8,4. Escala das barras nas Figuras 5 e $6=50 \mu \mathrm{m}$.
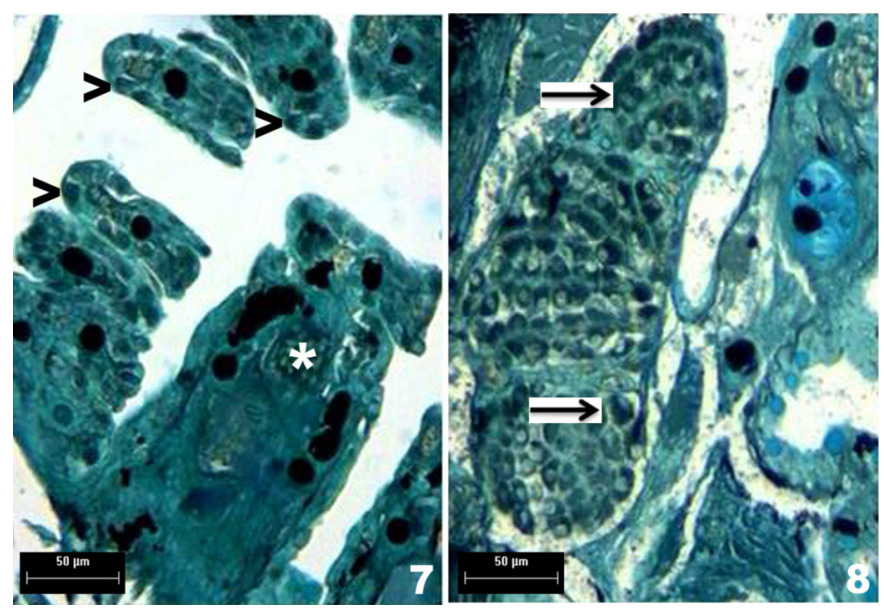

Fig.7-8. (7) Brânquias de embrião (Fase 3) em secção transversal (esquerda da imagem) e longitudinal (direita da imagem). Verificam-se as CRM pouco reativas ao ZIO (>) e vaso sanguíneo branquial $\left(^{*}\right.$ ). Técnica: ZIO + AB pH 2,5. (8) Pseudobrânquia de embrião (Fase 3) em secção longitudinal. Destacam-se as CRMs sem óstio com forte marcação ao ZIO (setas). Técnica: $\mathrm{ZIO}+\mathrm{AB}$ pH 2,5. Escala das barras nas Figuras 5-8 = 50 $\mu \mathrm{m}$.

\section{DISCUSSÃO}

A pseudobrânquia de Poecilia reticulata possui lamelas e filamentos fundidos circundados por tecido conjuntivo, características que permitem a sua classificação como pseudobrânquia glandular, de acordo com Bridges et al. (1998). Além disso, esses autores afirmaram que a pseudobrânquia recoberta pelo epitélio faringiano é característica de alguns peixes de água doce da família Cyprinidae. 0 presente trabalho identificou a presença dessa estrutura glandular na família Poeciliidae.

O sistema vascular da pseudobrânquia de $P$. reticulata se apresentou morfologicamente semelhante àquele das holobrânquias. Os vasos sanguíneos no centro do filamento branquial das holobrânquias também se ramificam para a formação das lamelas branquiais, as quais possuem o epitélio respiratório (Pisam et al. 1980). Contudo, nos alevinos do guaru, a pseudobrânquia não possui lamelas branquiais livres, apresentam ausência do sistema de células pilares, sugerindo uma função não respiratória para esse órgão nas fases do desenvolvimento.

As células pseudobranquiais não apresentaram ósteo em sua membrana apical, ao contrário das CRM das holobrânquias. Essa especialização se assemelha à depressão na superfície apical e possui polissacarídeos sintetizados ou pelas CM branquiais, os quais após a sua produção são liberados sobre o epitélio branquial, ou pelas CRM. As CRM das holobrânquias de $P$. reticulata em água doce, anteriormente denominado de Lebistes reticulatus (Peters, 1859), e do peixe Mugil capito (Cuvier, 1829) em água salgada também possuem alta concentração de polissacarídeos na região apical, no sistema vesiculotubular e no complexo Golgiense. Desse modo, as CRM podem sintetizam parte dos glicoconjugados presentes em seu óstio (Pisam et al. 1980).

A marcação positiva do ósteo das CRM holobranquiais às lectinas STLB e LELB indica a presença de glicoconjugados contendo $\mathrm{N}$-acetilglicosamina nessa especialização de superfície apical, ao contrário das células pseudobran- 
quiais, tal como indicado por Rocha et al. (2010). Desse modo, provavelmente esses tipos celulares diferem quanto à fisiologia e às funções celulares, indicando papéis distintos da pseudobrânquia para a manutenção da homeostase corpórea, quando comparada às holobrânquias do guaru. As análises do tecido pseudobranquial marcado com ZIO permitiu confirmar que a pseudobrânquia glandular do guaru é composta por células com abundante sistema de biomembranas, provavelmente mitocôndrias e retículos endoplasmáticos lisos (Fig.7-8), tal como indica Watrin \& Mayer-Gostan (1996) e Schreiber \& Specker (1999). As análises ultraestruturais da pseudobrânquia de F. heteroclitus também indicaram que esse tipo celular possui grande quantidade de mitocôndrias, sistema vesiculotubular especializado, e extenso retículo endoplasmático liso associado com mitocôndrias e contínuo com a membrana plasmática basolateral (Copeland \& Dalton 1959).

Diante do exposto acima, o presente trabalho indica que os alevinos do guaru Poecilia reticulata possuem pseudobrânquia glandular constituída principalmente de células pseudobrânquiais em estado citofisiológico ativo, com abundante sistema de biomembranas e ausência da especialização de membrana apical, o ósteo, encontrado nas CRM das holobrânquias.

Agradecimentos.- Os autores agradecem ao Conselho Nacional de Desenvolvimento Científico e Tecnológico (CNPq) e à Universidade Federal de Goiás pelo apoio para execução do presente trabalho.

\section{REFERÊNCIAS}

Baatrup E. \& Junge M. 2001. Antiandrogenic Pesticides Disrupt Sexual Characteristics in the Adult Male Guppy (Poecilia reticulata). Environ. Health Perspect. 109:1063-1070.

Borges-de-Oliveira R., Rosa E.V., Nascimento V., Menezes-Faria J.C.N., Vigário A.F., Vieira P.M., Cardoso M.P., Breseghelo L., Menezes J.S., Mata J.R., Morais J.O.R. \& Sabóia-Morais S.M.T. 2006. Detection of Paraneuronal Cells in guppy (Poecilia vivipara) gill Filament Epithelium Determined by Histochemistry and Transmission Electron Microscopy. Revta Biol. Neotrop. 3:169-176.

Bridges C.R., Berenbrink M., Müller R. \& Waser W. 1998. Physiology and Biochemstry of the Pseudobranch: An Unanswered Question? Comp. Biochem. Physiol. A 119:67-77.

COBEA 1991. Princípios Éticos na Experimentação Animal. Colégio Brasileiro de Experimentação Animal. Disponível em <http://www.cobea. org.br/etica.htm\#3> Acesso em 26 jul. 2010.

Copeland D.E. \& Dalton A.J. 1959. An association between mitochondria and the endoplasmic reticulum in cells of the pseudobranch gland of a teleost. J. Biophys. Biochem. Cytol. 5:393-399.

Díaz A.O., Garcia A.N., Devincenti C.V. \& Goldemberg A.L. 2005. Ultrastructure and Histochemical Study of Glycoconjugates in the Gills of the White Croaker (Micropogonias furnieri). Anat. Histol. Embryol. 34:117-122.

Fanta E., Rios F.S.A., Romão S., Vianna A.C.C. \& Freiberger S. 2003. Histopathology of the fish Corydoras paleatus contaminated with sublethal levels of organophosphorus in water and food. Ecotoxicol. Environ. Safety 54:119-130.

Haubruge E., Petit F. \& Gage M.J.G. 2000. Reduced sperm counts in guppies (Poecilia reticulata) following exposure to low levels of tributyltin and bisphenol A. Proc. Royal Society B 267:2333-2337.

Karnovsky M.J. 1965. A formaldehyde-glutaraldehyde fixative of high osmolality for use in electron microscopy. J. Cell Biology 27:137-138.

Ke W.M., Xie S.B., Yu L.N., Liu T., Lai J., He D.Q., Li X.H., Gao Z.L., Ke Y. \& Chen P.J. 2007. Decline of serum HBV DNA and no change apportioned by the same hepatic parenchyma cell volume from hepatic fibrosis stage 1 to stage 4 during the natural history of chronic hepatitis B. Intervirol. 51:235-240.

Kinnberg K., Korsgaard B. \& Bjerregaard P. 2003. Effects of octylphenol and $17 \beta$-estradiol on the gonads of guppies (Poecilia reticulata) exposed as adults via the water or as embryos via the mother. Comp. Biochem. Physiol. C 134:45-55.

Larini L. 1979. Toxicologia dos Inseticidas. Sarvier, São Paulo.

Machado M.R. \& Fanta E. 2003. Effects of the Organophosphorous Methyl Parathian on the Branchial Epithelium of a Freshwater fish Metynnis roosevelti. Braz. Archs Biol.ogy Technol. 43:361-372.

OECD 1992. Test 203: fish acute toxicity test. Disponível em <http://www. oecd.org/chemicalsafety/risk-assessment/1948241.pdf> Acesso em 10 de dezembro de 2013.

Paffaro Jr V.A., Bizinotto M.C., Joazeiro P.P. \& Yamada A.T. 2003. Subset classification of mouse uterine natural killer cells by DBA lectin reactivity. Placenta 24:479-488.

Pisam M., Sardet C. \& Maetz J. 1980. Polysaccharidic material in chloride cell of teleostean gill: modifications according to salinity. Am. J. Physiol. 238:213-218.

Pough F.H., Heiser J.B. \& McFarland W.N. 1999. A vida dos vertebrados. $2^{\underline{a}}$ ed. Atheneu, São Paulo. 801p.

Rocha T.L., Carvalho R., Yamada A.T. \& Sabóia-Morais S.M.T. 2010. Morphologic analysis of developmental phases and gill ontogenesis in neotropical species Poecilia vivipara (Cyprinodontiformes: Poeciliidae) exposed to different salinities. Zoologia 27:554-562.

Sabóia-Moraes S.M.T., Hernandes-Blazquez F.J., Mota D.L., Bittencourt A.M. 1996. Mucous cell types in the branchial epithelium of the euryhaline fish Poecilia vivipara. J. Fish Biology 49:545-548.

Schreiber A.M. \& Specker J.L. 1999. Metamorphosis in the summer flounder Paralichthys dentatus: changes in gill mitochondria.rich cells. J. Exp. Biology 202:2475-2482.

Vertemati M., Vizzotto L., Moscheni C., Dhillon A., Dhillon A., Quaglia A. 2008. Morphometric model to minimize subjectivity in the histological assessment of hepatocellular carcinoma and its precursors in cirrhosis. Microscopy Res. Tech. 71:606-613.

Vigliano F.A., Aleman N., Quiroga M.I. \& Nieto J.M. 2006. Ultrastructural Characterization of Gills in Juveniles of the Argentinian Silverside, Odontesthes bonariensis (Valenciennes, 1835) (Teleostei: Atheriniformes). Anat. Histol. Embryol. 35:76-83.

Watrin A. \& Mayer-Gostan N. 1996. Simultaneous Recognition of Ionocytes and Mucous Cells in the Gill Epithelium of Turbot and in the Rat Stomach. J. Exp. Zoology 276:95-101.

Wilkie M.P. 1997. Mechanisms of amnonia excretion across fish gills. Comp. Biochem. Physiol. A 118:39-50.

Yilmaz M., Gül A. \& Karaköse E. 2004. Investigation of acute toxicity and the effect of cadmium chloride $\left(\mathrm{CdCl}_{2} \cdot \mathrm{H}_{2} \mathrm{O}\right)$ metal salt on behavior of the guppy (Poecilia reticulata). Chemosphere 56:375-380. 